\title{
Improvement in the signs and symptoms of dry eye disease with dobesilate eye drops
}

\author{
Pedro Cuevas ${ }^{1,2^{*}}$, Luis Antonio Outeiriño ${ }^{2}$, Carlos Azanza ${ }^{2}$, Javier Angulo ${ }^{3}$ and Guillermo Giménez-Gallego ${ }^{4}$
}

\begin{abstract}
Background: Dry eye is a multifactor disease of the tear film and ocular surface that substantially affects quality of life.

Case presentation: Dobesilate administered as eye drops was well tolerated and effective in treating both the objective signs and subjective symptoms of dry eye disease in this 2-week study.

Conclusion: To the best of our knowledge, this is the first clinical report of using dobesilate in eye drops. Dobesilate may provide a novel approach to treating drying diseases of the eye.
\end{abstract}

Keywords: Dry eye disease, Dobesilate eye drops, Fibroblast growth factor, Vascular endothelial growth factor

\section{Background}

Dry eye disease (DED) is a progressive and multifactorial disease affecting the tear film and ocular surface that causes discomfort, visual disturbances and tear film instability with potential damage to the ocular surface [1]. DED is one of the most common ophthalmic problems, and it is estimated that up to one-third of the global population may be affected. Although the pathogenesis of DED is not fully understood, it is recognized that inflammation has a prominent role in the development and amplification of the signs and symptoms of DED [2-5]. Accordingly, successful application of anti-inflammatory medications in the treatment of DED provides hope for the millions of individuals who suffer from this deleterious condition. Herein, we report the safety and effectiveness of topical administration of the anti-inflammatory drug dobesilate [6-9] in patients with severe DED.

\section{Patients and treatment}

Eight patients (seven women and one man) with severe DED in both eyes participated in this study. The study was approved by our institutional ethical committee, and patients signed an informed consent form that included

\footnotetext{
* Correspondence: pedro.cuevas44@gmail.com

${ }^{1}$ Facultad de Medicina, Universidad Alfonso X, Madrid, Spain

2Departamento de Oftalmología, Hospital de Día Pío XII, Madrid, Spain

Full list of author information is available at the end of the article
}

a comprehensive description of the proposed procedure with dobesilate. Patients were asked before and during treatment to describe the DED symptoms they experienced. DED symptoms (foreign body sensation, dryness, photophobia, eye pain, and blurred vision) were scored from 0 to 4, with a score of 0 indicating no symptoms and a score of 4 indicating very severe symptoms. DED signs were assessed by Schirmer's tear test (STT) and by fluorescence corneal staining (FCS). STT performed without anesthesia measures tear volume. For FCS, $5 \mu \mathrm{l}$ of $0.5 \%$ fluorescein solution was instilled in the conjunctival sac. Fluorescein diffuses rapidly into the corneal stroma when there is a loss of epithelial integrity. Corneal staining was examined under standard illumination using a slit-lamp microscope with a cobalt filter. All patients initially had STT scores $<5 \mathrm{~mm} / 5 \mathrm{~min}$ and corneal epitheliopathy in both eyes. DED symptom scores and signs were compared at baseline, the second week of treatment, and 4 weeks after treatment discontinuation.

Furthermore, patient satisfaction scores were assessed during treatment using four questions adapted from the Study Group on Impact of Dry Eye on Everyday Life (IDEEL) questionnaire [10], with minor modifications. The four questions included the following: 1) my eyes feel dry in the morning, 2) my eyes feel dry at the end of the day, 3) my eyes feel refreshed when I use dobesilate, 
and 4) I frequently forget my symptoms when I use dobesilate.

Patients consented to treatment with dobesilate eye drops, which were prepared in the pharmacy service of our institution. Patients self-administered dobesilate eye drops (1 drop/eye/twice a day) for 2 weeks. Dobesilate was used as a $12.5 \%$ solution of diethylammonium 25-dihydroxybenzene sulfonate (etamsylate, Dicynone, Sanofi-Aventis, Paris, France). Quantitative comparisons between baseline and post-treatment symptom scores were performed for 16 eyes (8 patients) using paired t-tests. A p value less than 0.05 was considered statistically significant.

Symptoms of DED were significantly improved in all patients after treatment (Fig. 1). In addition, STT and corneal epitheliopathy assessed by FCS studies improved significantly. Furthermore, patients exhibited good compliance and did not report any adverse effects related to dobesilate treatment. As an example of the effectiveness of dobesilate eye drops, we present a patient with severe DED who participated in the present study.

\section{Case presentation}

This is a representative case selected from among the eight patients with DED who were treated with dobesilate eye drops. A 68-year-old Caucasian woman with a five-year clinical history of DED in both eyes presented with obvious ocular symptoms. The patient had been previously treated with artificial tears, but without success. STT scores were $<5 \mathrm{~mm} / 5 \mathrm{~min}$ in both eyes. Punctuate epithelial erosions on the inferior corneal surface were present in both eyes (Fig. 2). These punctuate corneal epitheliopathies were most noticeable in the right eye (Fig. 2). Furthermore, the right eye showed a conspicuous corneal erosion (Fig. 2). These findings indicated a severe DED.

After 2 weeks of dobesilate treatment, STT scores improved in both eyes to $12 \mathrm{~mm} / 5 \mathrm{~min}$ in the right eye and $15 \mathrm{~mm} / 5 \mathrm{~min}$ in the left eye. Corneal epitheliopathy improved as well, and corneal healing was practically achieved at the same time (Fig. 2). In addition, the patient's subjective symptoms improved significantly after 2 weeks of treatment. At 4 weeks after treatment discontinuation, the STT score was $15 \mathrm{~mm} / 5 \mathrm{~min}$ in the right eye and $20 \mathrm{~mm} / 5 \mathrm{~min}$ in the left eye, and the corneal ulceration of the right eye was healed (Fig. 3). The patient exhibited good compliance to dobesilate treatment; the data showed optimal tolerability, a lack of adverse effects upon instillation and high patient satisfaction. In particular, the patient did not report any adverse events of blurring, itching or scratching upon instillation. Instead, the patient reported a statistically significant reduction in all subjective symptoms. Objective and subjective data were recorded at 4 weeks after treatment discontinuation, and the patient reporting using artificial tears only sporadically.

\section{Discussion and conclusion}

Dry eye is defined by the International Dry Eye Workshop as a multifactor disease of the tear film and ocular surface [1] that substantially affects quality of life because of symptoms that include pain and irritation. DED has a negative effect on ocular health and the patient's general
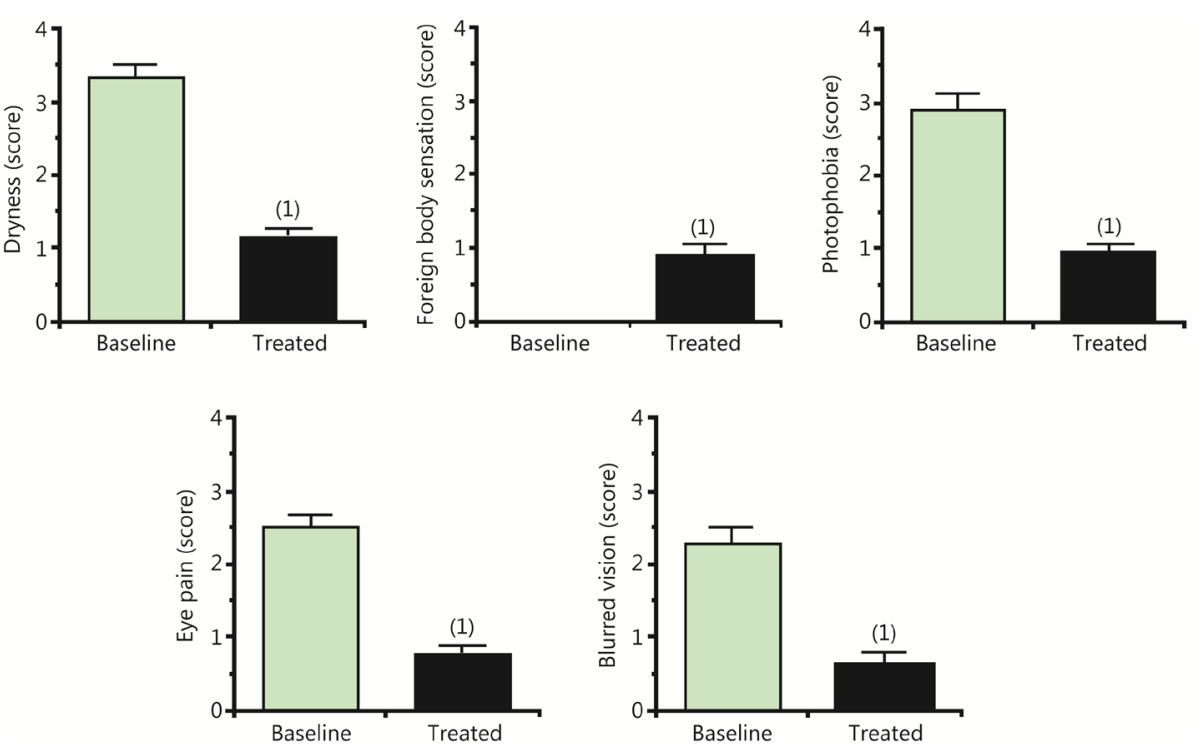

Fig. 1 Improvement of dry eye symptoms after dobesilate eye drop instillation for two weeks. Data from 16 eyes (8 patients) are expressed as the mean \pm SEM *** indicate $p<0.001$ vs. baseline by paired $t$-test 


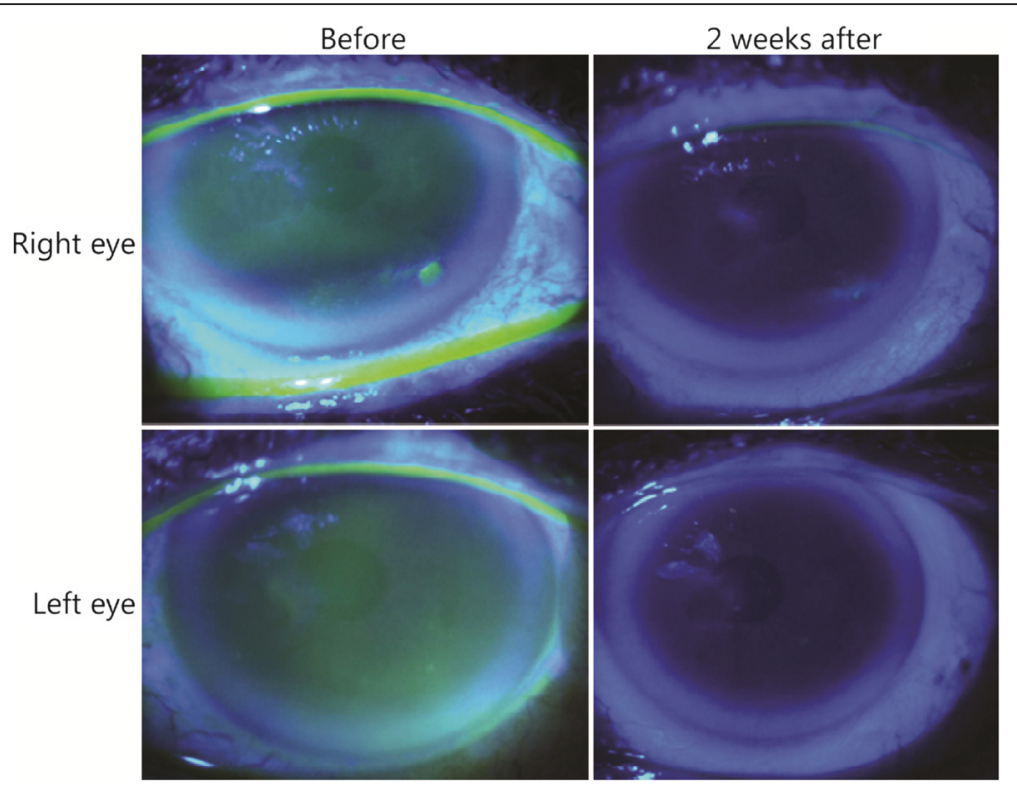

Fig. 2 Slit-lamp fluorescein corneal staining pictures showed that inferior corneal punctuate epitheliopathy disappeared within 2 weeks of the instillation of dobesilate eye drops. The corneal erosion $\left(^{*}\right)$ improved 2 weeks after administration of the drug

health and well-being, as DED often disrupts daily activities $[11,12]$. This condition is more prevalent in women and increases with age. The prevalence of DED in the population has been reported to be as high as $34 \%$ $[13,14]$, constituting a public health problem and an economic burden [15]. Risk factors for the development of DED include advanced age, female sex, hormonal imbalance, autoimmune disease, vitamin deficiency, abnormal corneal innervation, environmental stress, contact lens use, medication, computer use, and ophthalmic surgery $[8]$.

The ocular surface (cornea, conjunctiva and accessory lachrymal glands), meibomian glands, main lachrymal gland and interconnecting neural reflex loops constitute

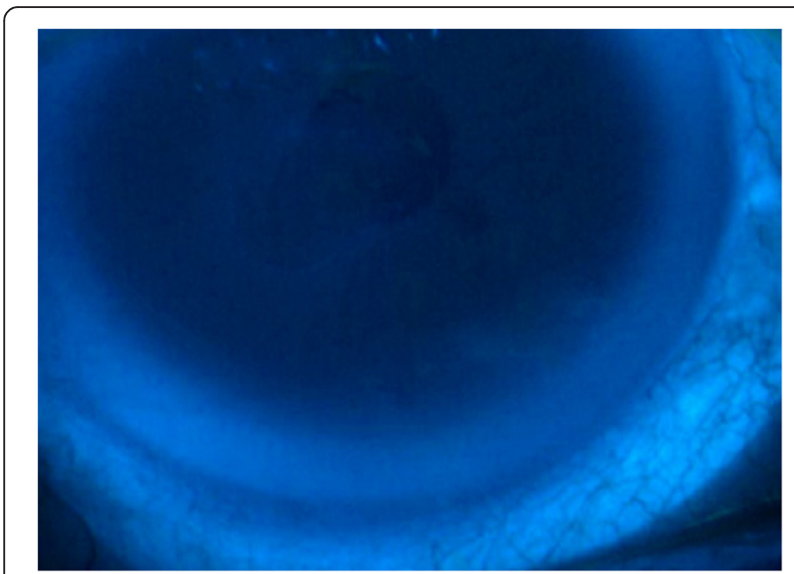

Fig. 3 Slit-lamp fluorescein corneal staining image of the right eye showing complete resolution of corneal ulceration 4 weeks after treatment discontinuation a functional unit [16]. In DED, inflammation affects all of the components in the functional unit, which suggests that immunological circuits are an integrate part of the system [2, 17, 18]. Its central core is characterized by cyclic events that interconnect tear film instability, tear hyperosmolarity, local inflammatory responses and metaplastic changes in the ocular surface epithelia. The purpose of any therapeutic approach is to interrupt this type of cycle at any point to slow or prevent the disease progression [8].

The recommended treatments for mild DED are lifestyle changes and use of artificial tears [17]; however, frequent instillation is often required. Furthermore, patients with moderate to severe disease may require antiinflammatory medications or surgery [17]. Cyclosporine ophthalmic emulsion has been approved by the United States Food and Drug Administration for treating moderate to severe DED. Clinical data indicate that longterm treatment with cyclosporine A $0.05 \%$ ophthalmic emulsion can yield positive results with regard to objective and subjective findings, including corneal surface staining, STT scores, blurred vision, and frequency of artificial tear application [19]. However, some patients experience bothersome adverse effects (e.g., pain, burning or irritation) that impact medication tolerability. Topical corticosteroid treatment has demonstrated efficacy in clinical trials at diminishing symptom severity and minimizing ocular surface staining in patients with DED [20, 21]. Systemic corticosteroid administration may also be effective in the management of DED [22]. Unfortunately, long-term topical or systemic corticosteroid use is associated with deleterious adverse effects, 
such as ocular hypertension, risk of cataract formation and opportunistic infections. Orally administered antiinflammatory tetracycline derivatives have been used to treat DED secondary to ocular rosacea and blepharitis [23]. However, despite extensive evidence from experimental trials indicating their potential benefits in treating DED, there is limited clinical evidence of their efficacy.

Because existing DED treatments have serious concerns, the search for a safe and efficient therapy for DED is urgently needed. Inflammation of the ocular surface in DED is sustained by ongoing activation and infiltration of pathogenic immune cells, primarily of the $\mathrm{CD} 4+\mathrm{T}$ cell compartment [24]. These biological processes were favored and maintained by lymphangiogenesis [25]. Interestingly, targeting prolymphangiogenic growth factors, such as vascular endothelial growth factor (VEGF), or their receptors improved murine DED, which is reflected by decreased inflammation [26]. It was reported that fibroblast growth factor (FGF) simultaneously provokes hemangiogenesis and lymphangiogenesis on the cornea through differential expression of VEGF [27]. Thus, inhibition of FGF-driving inflammatory lymphangiogenesis is a potential therapeutic target for DED.

Dobesilate, a drug with a long history of clinical safety [28], has been used for many years as a vasculotropic drug. Recently, it was reported that dobesilate is a powerful inhibitor of FGF [29], which is a potent proinflammatory protein [30,31]. FGF is a strict mediator of VEGF activities [29, 32, 33], and some of these activities were also abolished by dobesilate [34]. Dobesilate shows a marked anti-inflammatory activity in several inflammation-dependent diseases and inflammation models [6-9]. Thus, it seems obvious that these activities may, at least in part, contribute to an improvement in the signs and symptoms of DED, which was observed with dobesilate treatment in the present report.

The results of our study are very encouraging because of the magnitude and consistency of the patients' responses to the treatment and the rarity of spontaneous improvements in patients with DED. Although further large-scale therapeutic trials are necessary to definitively establish the efficacy of this treatment, the results presented in this report seem to provide a basis for undertaking these trials.

\section{Consent}

Written informed consent for publication of the clinical details and images was obtained.

\section{Abbreviations}

DED: dry eye disease; FCS: fluorescence corneal staining; FGF: fibroblast growth factor; IDEEL: impact of dry eye on everyday life; STT: Schirmer's tear test; VEGF: vascular endothelial growth factor.

\section{Authors' contributions}

PC and GGG wrote the paper. JA performed the statistical study. LO and CA examined patients. All authors have participated in the concept, design/ analysis and interpretation of data, drafting and revising the manuscript.

They have given final approval for the manuscript.

\section{Author details}

${ }^{1}$ Facultad de Medicina, Universidad Alfonso X, Madrid, Spain. ${ }^{2}$ Departamento de Oftalmología, Hospital de Día Pío XII, Madrid, Spain. ${ }^{3}$ Servicio de Histología. Departamento de Investigación, IRYCIS; Hospital Universitario Ramón y Cajal, Madrid, Spain. ${ }^{4}$ Departamento de Estructura y Función de Proteínas, Centro de Investigaciones Biológicas. CSIC, Madrid, Spain.

Received: 14 August 2014 Accepted: 15 December 2015

Published online: 21 December 2015

\section{References}

1. No authors listed. The definition and classification of dry eye disease: report of the Definition and Classification Subcommittee of the International Dry Eye WorkShop (2007). Ocul Surf. 2007; 5: 75-92.

2. Stern ME, Pflugfelder SC. Inflammation in dry eye. Ocul Surf. 2004;2:124-30.

3. Hessen M, Akpek EK. Dry eye: an inflammatory ocular disease. J Ophthalmic Vis Res. 2014;9:240-50.

4. Wei $Y$, Asbell PA. The core mechanism of dry eye disease is inflammation. Eye Contact Lens. 2014;40:248-56.

5. Niu L, Zhang S, Wu J, Chen L, Wang Y. Upregulation of NLRP3 inflammasome in the tears and ocular surface of dry eye patients. PLoS One. 2015;10:e0126277.

6. Piller NB. Assessment of the anti-inflammatory action of calcium dobesilate. Effect on macrophages attaching to subcutaneously implanted coverslips in guinea pigs. Arzneimittelforschung. 1990;40:698-700.

7. Cuevas P, Angulo J, Giménez-Gallego G. Long-term effectiveness of dobesilate in the treatment of papulopustular rosacea. BMJ Case Rep. 2011. doi:10.1136/bcr.08.2011.4579.

8. Cuevas P, Angulo J, Giménez-Gallego G. Topical treatment of contact dermatitis by pine processionary caterpillar. BMJ Case Rep. 2011;2011. doi: 10.1136/bcr.06.2011.4351.

9. Angulo J, Cuevas P, Cuevas B, El Youssef M, Fernández A, Martínez-Salamanca $E$, et al. Diacetyloxyl derivatization of the fibroblast growth factor inhibitor dobesilate enhances its anti-inflammatory, anti-angiogenic and anti-tumoral activities. J Transl Med. 2015;13:48. doi:10.1186/s12967-015-0413-4

10. Abetz L, Rajagopalan K, Mertzanis P, Begley C, Barnes R, Chalmers R. Impact of dry eye on everyday Life (IDEEL) study group. Development and validation of the impact of dry eye on everyday life (IDEEL) questionnaire, a patient-reported outcomes (PRO) measure for the assessment of the burden of dry eye on patients. Health Qual Life Outcomes. 2011;9:111. doi:10.1186/1477-7525-9-111.

11. No authors listed. Management and therapy of dry eye disease: report of the Management and Therapy Subcommittee of the International Dry Eye WorkShop (2007). Ocul Surf. 2007; 5: 163-78.

12. Miljanović B, Dana R, Sullivan DA, Schaumberg DA. Impact of dry eye syndrome on vision-related quality of life. Am J Ophthalmol. 2007;143:409-15.

13. Lin PY, Tsai SY, Cheng CY, Liu JH, Chou P, Hsu WM. Prevalence of dry eye among an elderly Chinese population in Taiwan: the Shihpai Eye Study. Ophthalmology. 2003;110:1096-101.

14. Schaumberg DA, Sullivan DA, Buring JE, Dana MR. Prevalence of dry eye syndrome among US women. Am J Ophthalmol. 2003;136:318-26.

15. Reddy P, Grad O, Rajagopalan K. The economic burden of dry eye: a conceptual framework and preliminary assessment. Cornea. 2004;23:751-61.

16. Stern ME, Beuerman RW, Fox RI, Gao J, Mircheff AK, Pflugfelder SC. The pathology of dry eye: the interaction between the ocular surface and lacrimal glands. Cornea. 1998;17:584-9.

17. Stevenson W, Chauhan SK, Dana R. Dry eye disease: an immune-mediated ocular surface disorder. Arch Ophthalmol. 2012;130:90-100.

18. Gayton JL. Etiology, prevalence, and treatment of dry eye disease. Clin Ophthalmol. 2009;3:405-12.

19. Stevenson D, Tauber J, Reis BL. Efficacy and safety of cyclosporin a ophthalmic emulsion in the treatment of moderate-to-severe dry eye disease: a dose-ranging, randomized trial. The cyclosporin a phase 2 study group. Ophthalmology. 2000;107:967-74. 
20. Marsh P, Pflugfelder SC. Topical nonpreserved methylprednisolone therapy for keratoconjunctivitis sicca in Sjögren syndrome. Ophthalmology. 1999;106:811-6.

21. Avunduk AM, Avunduk MC, Varnell ED, Kaufman HE. The comparison of efficacies of topical corticosteroids and nonsteroidal anti-inflammatory drops on dry eye patients: a clinical and immunocytochemical study. Am J Ophthalmol. 2003;136:593-602.

22. Cordero-Coma M, Anzaar F, Sobrin L, Foster CS. Systemic immunomodulatory therapy in severe dry eye secondary to inflammation. Ocul Immunol Inflamm. 2007;15:99-104.

23. Seal DV, Wright P, Ficker L, Hagan K, Troski M, Menday P. Placebo controlled trial of fusidic acid gel and oxytetracycline for recurrent blepharitis and rosacea. Br J Ophthalmol. 1995;79:42-5.

24. Stern ME, Gao J, Schwalb TA, Ngo M, Tieu DD, Chan CC, et al. Conjunctival T-cell subpopulations in Sjögren's and non-Sjögren's patients with dry eye. Invest Ophthalmol Vis Sci. 2002;43:2609-14.

25. Goyal S, Chauhan SK, El Annan J, Nallasamy N, Zhang Q, Dana R. Evidence of corneal lymphangiogenesis in dry eye disease: a potential link to adaptive immunity? Arch Ophthalmol. 2010;128:819-24.

26. Goyal S, Chauhan SK, Dana R. Blockade of prolymphangiogenic vascular endothelial growth factor $\mathrm{C}$ in dry eye disease. Arch Ophthalmol. 2012:130:84-9

27. Hajrasouliha AR, Sadrai Z, Chauhan SK, Dana R. b-FGF induces corneal blood and lymphatic vessel growth in a spatially distinct pattern. Cornea. 2012;31:804-9.

28. Allain $\mathrm{H}$, Ramelet AA, Polard E, Bentué-Ferrer D. Safety of calcium dobesilate in chronic venous disease, diabetic retinopathy and haemorrhoids. Drug Saf. 2004;27:649-60.

29. Fernández IS, Cuevas P, Angulo J, López-Navajas P, Canales-Mayordomo A, Lozano RM, et al. Gentisic acid, a compound associated with plant defence and a metabolite of aspirin, heads a new class of in vivo FGF inhibitor. J Bio Chem. 2010;285:1714-29.

30. Andrés $\mathrm{G}$, Leali $\mathrm{D}$, Mitola S, Coltrini D, Camozzi M, Corsini M, et al. A pro-inflammatory signature mediates FGF2-induced angiogenesis. J Cell Mol Med. 2009:13:2083-108.

31. Presta Y, Andrés G, Leali D, Dell'Era P, Ronca R. Inflammatory cells and chemokines sustain FGF2-induced angiogenesis. Eur Cytokine Netw. 2009;20:39-50

32. Jonca F, Ortega N, Gleizes PE, Bertrand N, Plouet J. Cell release of bioactive fibroblast growth factor 2 by exon 6 encoded sequence of vascular endothelial growth factor. J Biol Chem. 1997;272:24203-9.

33. Mandriota SJ, Pepper MS. Vascular endothelial growth factor-induced in vitro angiogenesis and plasminogen activator expression are dependent on endogenous basic fibroblast growth factor. J Cell Sci. 1997;110:2293-302.

34. Angulo J, Peiró C, Romacho T, Fernández A, Cuevas B, González-Corrochano R, et al. Inhibition of vascular endothelial growth factor (VEGF)-induced endothelial proliferation, arterial relaxation, vascular permeability and angiogenesis by dobesilate. Eur J Pharmacol. 2011;667:153-9.

\section{Submit your next manuscript to BioMed Central and we will help you at every step:}

- We accept pre-submission inquiries

- Our selector tool helps you to find the most relevant journal

- We provide round the clock customer support

- Convenient online submission

- Thorough peer review

- Inclusion in PubMed and all major indexing services

- Maximum visibility for your research

Submit your manuscript at www.biomedcentral.com/submit

) Biomed Central 